\title{
From conjugated tertiary skipped diynes to chain-functionalized tetrasubstituted pyrroles
}

\author{
David Tejedor, ${ }^{[\mathrm{a}][\mathrm{b}]}$ * Sara López-Tosco, ${ }^{[\mathrm{a}][\mathrm{b}]}$ Javier González-Platas ${ }^{[\mathrm{c}]}$ and Fernando García- \\ Tellado ${ }^{[\mathrm{a}] \mathrm{b}]}$
}

\begin{abstract}
Among the most appreciated chemical complexity-generating reactions, domino processes ${ }^{[1]}$ maintain a privileged status. They perform molecular complexity in a fast and efficient manner, accumulating important "green chemistry" values such as atom, time and labour economies, resource management and minimal chemical waste generation. ${ }^{[2]}$ An appealing subclass of domino processes comprises the reaction of a densely and conveniently functionalized acyclic scaffold with a simple and readily accessible chemical reactant (amine, alcohol, C-nucleophiles, etc.). ${ }^{[3]}$ The design and synthesis of these scaffolds constitutes a sought-after challenge in current organic synthesis and more specifically, in drug discovery research. ${ }^{[4]}$ These densely functionalized structural units must be designed to accommodate three main practical requirements: a short synthesis (efficiency principle), a modular origin (diversity principle) and a defined interrelationship between functional groups (reactivity principle). Tertiary skipped diynes $\mathbf{1}$ fulfil these requirements. They are modularly assembled via the four-component $\mathbf{A}_{\mathbf{2}} \mathbf{B B}$ ' synthetic manifold shown in Fig $1^{[5,6]}$ Moreover, these $\mathrm{C}_{5}$ linear scaffolds feature an interconnected reactivity frame defined by the quaternary $\mathrm{sp}^{3}$-center and the two conjugated alkyne units. Whereas the quaternary center favours alkyne-mediated cyclization processes (Thorpe-Ingold effect) ${ }^{[7]}$ the
\end{abstract}

[a] Dr. D. Tejedor, Sara López-Tosco, Dr. F. García-Tellado Instituto de Productos Naturales y Agrobiología-CSIC Avda. Astrofísico Francisco Sánchez 3

38206 La Laguna, Tenerife, Spain

Fax: (+)34922-260135

E-mail: fgarcia@ipna.csic.es; dtejedor@ipna.csic.es

[b] Dr. D. Tejedor, Sara López-Tosco, Dr. F. García-Tellado Instituto Canario de Investigación del Cáncer htpp:/www.icic.es

[c] Dr. J. González-Platas

Servicio de Difracción de Rayos X

Departamento de Física Fundamental II

Universidad de La Laguna

Avda. Astrofísico Francisco Sánchez 2

38204 La Laguna, Tenerife, Spain. ester group allocated on this center and one of the two alkynoate units are conveniently oriented for a [3,3]-sigmatropic rearrangement. ${ }^{[8]}$ In addition, each alkynoate group holds a polyvalent reactivity profile which is expressed as $\mathbf{d}^{\mathbf{0}}, \mathbf{a}^{\mathbf{1}}, \mathbf{a}^{\mathbf{2}}, \mathbf{a}^{\mathbf{3}}, \mathbf{d}^{\mathbf{2}}$ and $\left[\mathbf{a}^{3}+\mathbf{d}^{2}\right]$ (letters refer to acceptor/donor properties while numbers refer to position) ${ }^{[9]}$ Each notation $\left(\mathbf{a}^{\mathbf{i}}, \mathbf{d}^{\mathbf{i}}\right)$ codifies for a particular chemical transformation at this specific position, i.e. $\mathbf{a}^{\mathbf{1}}$ codifies for 1,2-addition, $\mathbf{a}^{3}$ for 1,4-addition, and so on. We hypothesized that this rich arsenal of chemical transformations could be used as a convenient chemical toolbox for the design and implementation of different domino-based complexity-generating process involving these 1,4-diynic scaffolds (Figure 1).
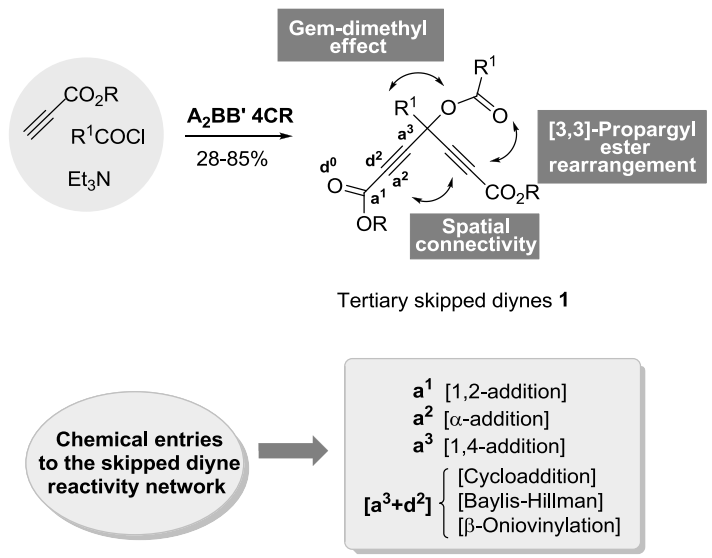

Figure 1. Synthesis and reactivity pattern of tertiary skipped diynes $\mathbf{1}$

As a proof of concept, we report herein our preliminary results on the design and implementation of an efficient and novel metalfree domino-based synthetic manifold for the transformation of tertiary skipped diynes $\mathbf{1}$ into chain-functionalized tetrasubstituted pyrroles 5 (Scheme 1). The chemical key to this domino process relies on the excellent Michael-acceptor character of the alkynoate functionality ( $\mathbf{a}^{\mathbf{3}}$-reactivity). ${ }^{[10]}$ The synthetic manifold operates in the absence of metals and it is triggered by the nucleophilic addition of a primary amine on the alkynoate function (aza- 
Michael-addition). An anti-Michael ${ }^{[11]}$ ring-closing hydroamination $^{[12]}$ followed by a [3,3]-sigmatropic rearrangement completes the process to generate the pyrrole 5. The strategically placed oxygenated functionality at the quaternary $\mathrm{sp}^{3}$-center accomplishes two important tasks: it favors the 5-endo-dig cyclization (gem-dimethyl effect), and once the ring forms, it drives the process to completion via an aromatization-driven [3,3]sigmatropic rearrangement. ${ }^{[13]}$ Overall the process becomes a novel, two steps modular synthesis of chain-functionalized tetrasubstituted pyrroles from readily available alkyl propiolates, acid chlorides and primary amines. Whereas the multicomponent nature of the $\mathbf{A}_{\mathbf{2}} \mathbf{B B}$ ' manifold ensures a convenient grade of functional diversity in the 1,4-diyne, the subsequent bimolecular domino reaction generates a significant grade of structural complexity (one aromatic ring, one functionalized chain and four different substituents). To the best of our knowledge, this is the first example of a metal-free, two-step synthesis of these pyrroles from readily accessible starting materials. $^{[14]}$
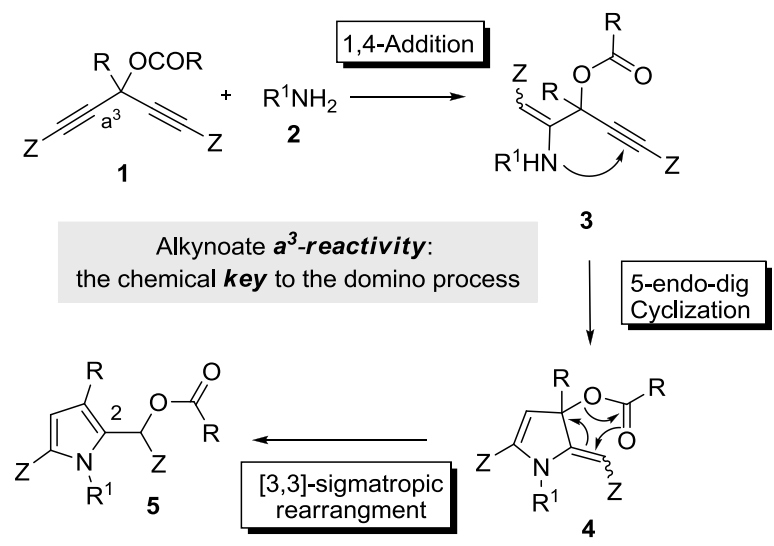

Scheme 1. Domino-based manifold for the synthesis of chain-functionalized tetrasubstituted pyrroles $5\left[\mathrm{Z}=\mathrm{CO}_{2} \mathrm{R}^{2}\right]$.

Chain functionalized pyrroles constitute a structural motif of particular interest in synthetic and medicinal chemistry, as it is the foundation of important medicines, natural products and synthetic materials. ${ }^{[15]}$ In particular, tetrasubstituted pyrroles $\mathbf{5}$ can be considered as hybrid scaffolds ${ }^{[16]}$ comprising a structurally privileged pyrrole ring and a natural-occurring $\alpha$-hydroxy acid motif. $^{[17]}$ The hybrid features five points of diversity (two chemodifferentiated ester groups, two chemo-differentiated $\mathrm{R}$ groups and one $\mathrm{N}-\mathrm{R}^{1}$ group) and two differentiated points for complexity generation: one on the ring $\left(\mathrm{sp}^{2}\right.$-linking point; $\left.\mathrm{C} 4-\mathrm{H}\right)$ and the other on the chain [ $\mathrm{sp}^{3}$-linking point; $\left.\mathrm{CH}(\mathrm{OCOR}) \mathrm{Z}\right]$ (Figure 2).

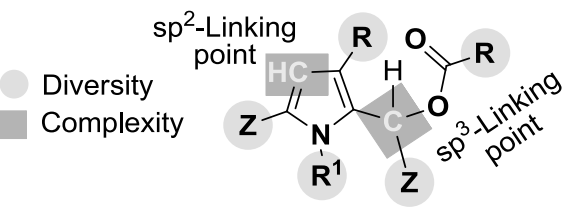

Figure 2. Graphical representation of the 5 points of diversity and the 2 points for generation of complexity present in pyrrole 5 .
These hybrid structures are usually synthesized via FriedelCrafts reaction between the substituted pyrrole and the corresponding alkyl glyoxylate. ${ }^{[18,19]}$ During the last years, a number of important organometallic methodologies for the synthesis of pyrroles from alkyne-containing materials have been developed. ${ }^{[20]}$ Paradoxically, the number of metal-free homologous methodologies has remained scarce. ${ }^{[21]}$ This scarcity offers a convenient challenge for the design and implementation of novel synthetic methodologies in line with the newest tendencies in organic synthesis ${ }^{[22]}$ and drug discovery research. ${ }^{[4]}$ Herein, we report our preliminary contribution to this challenge with the design and implementation of a novel, metal-free, modular and direct synthetic manifold to gain access to these important structural motives. The manifold was implemented studying the reaction of 1,4-diyne $1 \mathbf{a}\left(\mathrm{Z}=\mathrm{CO}_{2} \mathrm{Me} ; \mathrm{R}=\mathrm{Ph}\right)$ with benzylamine (2a) [Eq. (1)]. After some experimental work, we pleasantly found that diyne $\mathbf{1 a}$ reacted with amine $\mathbf{2 a}$ in dichloroethane and under reflux conditions $(5 \mathrm{~h})$ to afford pyrrole 5 aa in good yield $(74 \%)$. Changing conventional heating by microwave heating $\left(100 \text { watt, } 100^{\circ} \mathrm{C} \text {, closed vessel }\right)^{[23]}$ delivered pyrrole 5aa in a shorter period of time $(30 \mathrm{~min})$ but with a light erosion in the reaction efficiency (70\% yield). With these satisfactory experimental conditions at hand, we next studied the reaction scope with regard to both components (Table 1). As a general tendency, the conventional heating proved to be slightly more effective than microwave heating (entries 1-4, 6, 8, 9 and 11). With regard to the substituents at the 1,4-diyne component, the reaction proved to be tolerant with both aromatic and aliphatic groups. As expected, the electronic nature of the aromatic ring does not have a definitive influence on the reaction efficiency (compare entries 1,2 and 5). With regard to aliphatic substituents, they are limited to secondary or tertiary by the 1,4-diyne's own construction manifold. ${ }^{[5]}$ Whereas 1,4-diynes bearing secondary alkyl substituents participate with similar chemical efficiency to the aromatic homologues (compare entries 1-5 and 9-12), those bearing tertiary

Table 1. Domino synthesis of pyrroles $\mathbf{5}$ from tertiary skipped diynes $\mathbf{1}$ and primary amines 2. ${ }^{[a]}$
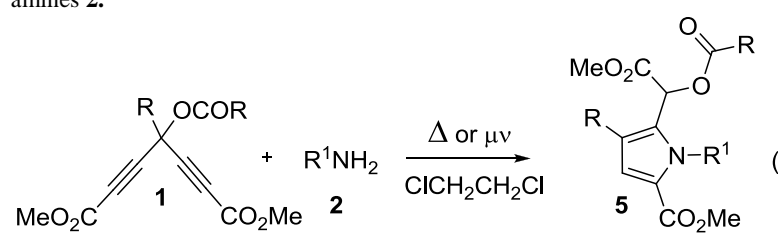

\begin{tabular}{|c|c|c|c|c|c|c|c|}
\hline Entry & $\mathrm{R}$ & & $\mathrm{R}^{1}$ & & & $\Delta(\%)^{[b]}$ & $\mu v(\%)^{[b]}$ \\
\hline 1 & $\mathrm{Ph}$ & $1 \mathrm{a}$ & $\mathrm{Bn}$ & $2 a$ & $5 a$ & 74 & 70 \\
\hline 2 & 4-Me $\mathrm{C}_{6} \mathrm{H}_{4}$ & $1 b$ & $\mathrm{Bn}$ & $2 a$ & $5 b$ & 66 & 54 \\
\hline 3 & 4,4'-BiPh & 1c & $\mathrm{Bn}$ & $2 a$ & $5 \mathrm{ca}$ & 61 & 59 \\
\hline 4 & 2- $\mathrm{ClC}_{6} \mathrm{H}_{4}$ & 1d & $\mathrm{Bn}$ & $2 a$ & $5 d$ & 74 & 72 \\
\hline 5 & $4-\mathrm{Cl} \mathrm{C} \mathrm{H}_{4}$ & 1e & $\mathrm{Bn}$ & $2 a$ & 5 ea & 72 & 84 \\
\hline 6 & $4-\mathrm{Cl} \mathrm{C} \mathrm{H}_{4}$ & 1e & $n \mathrm{Bu}$ & $2 b$ & $5 e$ & 73 & 71 \\
\hline 7 & 4- $\mathrm{Cl} \mathrm{C}{ }_{6} \mathrm{H}_{4}$ & $1 e$ & Allyl & $2 c$ & $5 \mathrm{ec}$ & 65 & 67 \\
\hline 8 & $\mathrm{Ph}$ & $1 a$ & $\mathrm{PEA}^{[\mathrm{c}]}$ & 2d & $5 a$ & $43^{[\mathrm{d}]}$ & $28^{[\mathrm{e}]}$ \\
\hline 9 & $c \mathrm{Hex}$ & 1f & $\mathrm{Bn}$ & $2 a$ & $5 \mathrm{fa}$ & 69 & 54 \\
\hline 10 & “ & “ & “ & “ & “ & - & $64^{[\mathrm{f}]}$ \\
\hline 11 & $i \operatorname{Pr}$ & $1 \mathrm{~g}$ & $\mathrm{Bn}$ & $2 a$ & $5 \mathrm{~g}$ & 68 & 66 \\
\hline 12 & “ & “ & “ & “ & “ & - & $71^{[\mathrm{g}]}$ \\
\hline
\end{tabular}


alkyl groups afford mixtures of unidentified compounds. Finally, the reaction requires a good nucleophilic amine to take place. Thus, whereas benzyl, n-butyl or allyl amines afforded the corresponding pyrroles in good yields, aromatic amines did not react under these experimental conditions (data not shown). Likewise, substitution at the $\alpha$-position of the aliphatic chain of the primary amine reduces its reactivity and therefore, the efficiency of the domino reaction (Entry 8). In this case, although the amine is chiral, the pyrrole derivative 5ad is obtained as a 1:1 mixture of diastereomers. Overall, the manifold constructs densely functionalized pyrroles $\mathbf{5}$ using a wide arsenal of primary amines and a broad range of substitution on the skipped diyne unit.

The pyrrole structure was unambiguously confirmed by an Xray crystallographic analysis of the carboxylic acid derivative 6 [Eq. (2)]. ${ }^{[24]}$ The synthesis of this derivative highlights the synthetic advantages associated with the breaking of symmetry performed by this synthetic manifold. Observe that the two identical ester functionalities of the starting 1,4-diyne are incorporated as two chemo-differentiated functionalities into the final pyrrole structure, allowing the chemoselective hydrolysis of pyrrole 5aa to acid 6 under standard conditions and without special chemical care $(\mathrm{LiOH}-$ THF- $\mathrm{H}_{2} \mathrm{O}$ ).<smiles></smiles><smiles></smiles>

With regard to the reaction mechanism, the following experimental observations support the participation of the reactive intermediates $\mathbf{3}$ and $\mathbf{4}$ and their postulated chemical transformations:

1) Reduction of the reaction time afforded variables mixtures of enamine 3 and pyrrole 5 (Scheme 1). ${ }^{[25]}$ This fact indicates that enamine formation is faster than the enamine cyclization, and that the latter constitutes the rate determinating step of this reaction network (anti-Michael addition).

2) Reaction of skipped diyne 7 with excess of benzylamine delivered the 5-membered ring compound $\mathbf{8}$ in $64 \%$ yield as a 2:1 mixture of $E: Z$ isomers (Scheme 2). The formation of this product emphasizes two important mechanistic questions: firstly, it reveals that the oxygenated function at the quaternary center does not have electronic influence on the course of the 5-endo-dig cyclization step; and secondly, it stresses the importance of an ester function to drive the process toward the pyrrole ring formation (aromatization).

3) Reaction of alcohol 9 with $n \mathrm{BuLi}$ and benzoyl chloride afforded pyrrole 5aa. This result confirms the liability of the tertiary ester group allocated on the 5-member ring and the postulated [3+3]sigmatropic rearrangement (Scheme 2).

In summary, we have reported on a novel and efficient metalfree methodology for the synthesis of chain-functionalized tetrasubstituted pyrroles $\mathbf{5}$ from easily accessible tertiary skipped diynes $\mathbf{1}$. The protocol utilizes a primary amine as the nitrogen

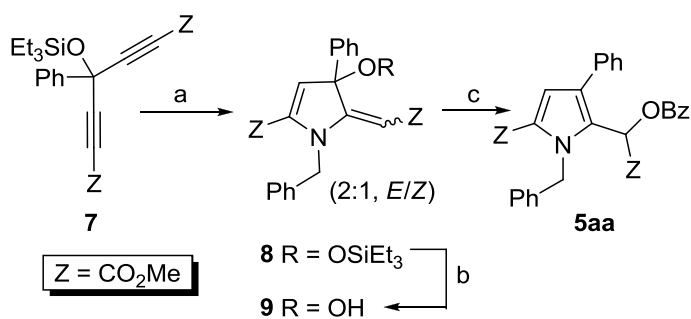

a) $\mathrm{BnNH}_{2}$ (1,4 equiv), $\mathrm{ClCH}_{2} \mathrm{CH}_{2} \mathrm{Cl}$, reflux, 3 days, $64 \%$; b) TBAF, THF, RT, $1 \mathrm{~h}, 47 \%$ (E-isomer); c) $n \mathrm{BuLi},-78^{\circ} \mathrm{C}$, THF, then $\mathrm{Bz}-\mathrm{Cl}, \mathrm{RT}, 1 \mathrm{~h}, 68 \%$.(Unoptimized yields). $\mathrm{TBAF}=$ tetrabutylammonium fluoride

Scheme 2. Three-step synthesis of pyrrole 5aa from 1,4-diyne 7.

source and the particular reactivity profile of the tertiary 1,4-diyne scaffolds to construct an efficient domino reaction involving an allowed 5-endo-digonal ring cyclization step and a complexitygenerating [3,3]-sigmatriopic rearrangement. The obtained tetrasubstituted pyrroles $\mathbf{5}$ are hybrid scaffolds densely functionalized and featuring five points of diversity and two points for generation of complexity. In addition, the synthetic manifold is atom and labor economical, and the reaction processing is benchfriendly and environmental-careful. The reaction can be performed under conventional or microwave heating conditions; whereas the former is faster (30 $\mathrm{min})$, the latter is slightly more efficient. The use of these hybrids motifs as polifunctionalized scaffolds for the development of building/coupling/pairing strategies ${ }^{[4]}$ are under study in our lab.

\section{Experimental Section}

Representative procedure (Table 1, entry 1):

a) Conventional heating: A solution of 1,4-diyne 1a $(1.0 \mathrm{mmol})$ and benzylamine (1.4 $\mathrm{mmol})$ in dichloroethane $(10 \mathrm{~mL})$ was heated under reflux conditions for $5 \mathrm{~h}$. Solvent was removed and the residue was flash-chromatographed on silica gel. Elution with ethyl acetate-hexanes 15-85 delivered pure pyrrole 5aa in 74\% yield.

b) Microwave heating: A solution of 1,4-diyne $1 \mathrm{a}(1.0 \mathrm{mmol})$ and benzylamine (1.4 $\mathrm{mmol})$ in dichloroethane $(4 \mathrm{~mL})$ was placed in a microwave-special closed vial and the solution was irradiated for $30 \mathrm{~min}$ in a single-mode microwave oven $\left(100 \mathrm{Watt}, 100^{\circ} \mathrm{C}\right)$. Same purification protocol delivered pure pyrrole $\mathbf{5 a a}$ in $70 \%$ yield.

${ }^{1} \mathrm{H}$ NMR $\left(400 \mathrm{MHz}, \mathrm{CDCl}_{3}\right): \delta=3.42(\mathrm{~s}, 3 \mathrm{H}), 3.75(\mathrm{~s}, 3 \mathrm{H}), 5.89\left(\mathrm{~d},{ }^{3} J(\mathrm{H}, \mathrm{H})=17.2 \mathrm{~Hz}\right.$, $1 \mathrm{H}), 5.95\left(\mathrm{~d},{ }^{3} J(\mathrm{H}, \mathrm{H})=17.2 \mathrm{~Hz}, 1 \mathrm{H}\right), 6.69(\mathrm{~s}, 1 \mathrm{H}), 6.89\left(\mathrm{~d},{ }^{3} J(\mathrm{H}, \mathrm{H})=7.2 \mathrm{~Hz}, 2 \mathrm{H}\right), 7.15-$ $7.20(\mathrm{~m}, 1 \mathrm{H}), 7.18(\mathrm{~s}, 1 \mathrm{H}), 7.24-7.30(\mathrm{~m}, 4 \mathrm{H}), 7.34\left(\mathrm{tt},{ }^{3} \mathrm{~J}(\mathrm{H}, \mathrm{H})=1.3,7.2 \mathrm{~Hz}, 1 \mathrm{H}\right), 7.39$ $7.45(\mathrm{~m}, 2 \mathrm{H}), 7.47-7.52(\mathrm{~m}, 3 \mathrm{H}), 7.65\left(\mathrm{~d},{ }^{3} \mathrm{~J}(\mathrm{H}, \mathrm{H})=7.7 \mathrm{~Hz}, 2 \mathrm{H}\right) ;{ }^{13} \mathrm{C}$ NMR $(100 \mathrm{MHz}$, $\left.\mathrm{CDCl}_{3}\right) \delta=49.5,51.4,52.8,66.2,118.1,124.1,125.2,126.8,127.3,128.1,128.3,128.5$, 128.6, 128.7, 129.1, 130.0, 133.4, 134.3, 138.7, 160.9, 165.1, 167.8. A $4^{\circ}$ carbon must be buried under a large peak in the aromatic region; IR $\left(\mathrm{CHCl}_{3}, \mathrm{~cm}^{-1}\right) 3030.0,1757.4$, 1720.6, 1452.1, 1256.4, 1222.1, 1167.1, 1092.9; MS (70 eV): $\mathrm{m} / \mathrm{z}(\%): 483(9.6)\left[\mathrm{M}^{+}\right]$, 318 (3.7), 302 (5.1), 105 (100), 91 (28), 77 (12); Anal. Calcd. for $\mathrm{C}_{29} \mathrm{H}_{25} \mathrm{NO}_{6}$ : C, 72.04; H, $5.21 ; \mathrm{N}, 2.90$. Found: C, 72.17; H, 5.37; N, 2.96; m.p. 59.4-60.3 ${ }^{\circ} \mathrm{C}$.

\section{Acknowledgements}

Authors thank the Spanish Ministerio de Educación y Ciencia and the European Regional Development Fund (CTQ2005-09074-C02-02), the Spanish MSC ISCIII (RETICS RD06/0020/1046), CSIC (Proyecto Intramural Especial 200719) and Fundación Instituto Canario de Investigación del Cáncer (FICI-G.I.No08/2007) for financial support. S. L.-T. Thanks MEC for a FPU grant. Authors thank technicians Sonia Rodriguez Díaz and Aida Sánchez López for preparation of starting materials.

Keywords: Pyrroles • Hybrid scaffolds • Domino•1,4-Diynes - Propargylic ester • 
[1] a) L. F. Tietze, G. Brasche, K. Gericke in Domino Reactions in Organic Synthesis, WILEY-VCH, Weinheim 2006; b) L. F. Tietze, Chem. Rev. 1996, 96, 115-136.

[2] a) P. Anastas, I. T. Horvath, Chem. Rev. 2007, 107, 2169-2173; b) P. T. Anastas, M. M. Kirchhoff, Acc. Chem. Res. 2002, 35, 686-694.

[3] For applications of these processes in total synthesis: K. C. Nicolaou, D. J. Edmonds, P. G. Bulger, Angew. Chem. 2006, 118, 7292-7344; Angew. Chem. Int. Ed. 2006, 45, 7134-7186

[4] For selected reviews on this topic: a) T. E. Nielsen, S. L. Schreiber, Angew. Chem. 2008, 120, 52-61; Angew. Chem. Int. Ed. 2008, 47, 48-56; b) G. L. Thomas, E. E. Wyatt and D. R. Spring, Curr. Opin. Drug Discovery Dev., 2006 9, 700-712; c) Curr. Opin. Chem. Biol. Special issue: "combinatorial chemistry", (Ed.: P. Arya, H.-J. Roth), 2005, 9, 232-331; d) C. M. Dobson, Nature 2004, 432 824-828; f) C. Lipinski, A. Hopkins, Nature 2004, 432, 855-861; g) G. Wess, M. Urmann, B. Sickenberger, Angew. Chem. 2001, 113, 3443-3453; Angew. Chem. Int. Ed. 2001, 40, 3341-3350

[5] D. Tejedor, S. López-Tosco, J. González-Platas, F. García-Tellado, J. Org Chem. 2007, 72, 5454-5456.

[6] $\quad \mathbf{A}_{2} \mathbf{B B}$ ' notation means that the reaction utilizes two different components (A and $\mathbf{B})$ to give a product which incorporates into its structure two identical units of component $\mathbf{A}\left(\mathbf{A}_{2}\right)$ and two chemo-differentiated units of component $\mathbf{B}(\mathbf{B}$ and B'). For full details and more examples of this type of multicomponent reactions: D. Tejedor, F. García-Tellado, Chem. Soc. Rev. 2007, 36, 484-491.

[7] R. M. Beesley, C. K. Ingold, J. F. Thorpe, J. Chem. Soc., 1915, 1080-1106.

[8] For [3,3]-propargylic ester rearrangements: N. Marion, S. P. Nolan, Angew. Chem. 2007, 119, 2806-2809; Angew. Chem., Int. Ed. 2007, 46, 2750-2752 and references cited therein.

[9] D. Tejedor, S. López-Tosco, F. Cruz-Acosta, G. Méndez-Abt, F. GarcíaTellado, Angew. Chem. Int. Ed., manuscript in press, DOI: 10.1002/anie. 200801987.

[10] M. E. Jung, in Comprehensive Organic Synthesis, (Eds.: B. M. Trost, I. Fleming, M. F. Semmelhack), Pergamon Press, Oxford, 1991.

[11] For a review: E. Lewandowska, Tetrahedron 2007, 63, 2107-2122.

[12] For a review: R. Severin, S. Doye, Chem. Soc. Rev. 2007, 36, 1407-1420.

[13] It has been recently described the metal catalyzed hydroamination of 3,3 dimethyl 1,4-diynes to generate a mixture of the corresponding 3,3-dimethy 3,4-dihydro- $2 \mathrm{H}$-pyrrole and 4,4-dimethyl-3,4-dihydropyridine derivatives. In this case, the all-carbon quaternary center favors the ring-cyclization step but inhibits the aromatization of the ring. V. Lavallo, G. D. Frey, B. Donnadieu, M Soleilhavoup, G. Bertrand, Angew. Chem. 2008, 120, 5302-5306; Angew. Chem. Int. Ed. 2008, 47, 5224-5228.

[14] For a precedent for metal-catalyzed synthesis of 1,2,5-trisubstituted pyrroles from simple 1,4-diynes: B. Ramanathan, A. J. Keith, D. Armstrong, A. L. Odom, Org. Lett. 2004, 6, 2957-2960.

[15] a) A. Fürstner, Angew. Chem. 2003, 115, 3706-3728; Angew. Chem. Int. Ed. 2003, 42, 3582-3603; b) C. T. Walsh, S. Garneau-Tsodikova, A. R. HowardJones, Nat. Prod. Rep. 2006, 23, 517-531; c) J. A. Pfefferkorn, D. M. Bowles, W. Kissel, D. C. Boyles, C. Choi, S. D. Larsen, Y. Song, K.-L. Sun, S. R. Miller, B. K. Trivedi, Tetrahedron 2007, 63, 8124-8134; d) J. A. Johnson, N.Li, D. Sames, J. Am. Chem. Soc. 2002, 124, 6900-6903; e) D. L. Boger, J. Hong, J. Am. Chem. Soc. 2001, 123, 8515-8519; f) P. W. Le Quesne, Y. Dong, T. A. Blythe in Alkaloids: Chemical and Biological Perspectives, (Ed. S. W. Pelletier),

Received: ((will be filled in by the editorial staff))

Revised: ((will be filled in by the editorial staff))

Published online: ((will be filled in by the editorial staff))
Pergamon: Elmsford, New York, 1999; g) M. Lehr, J. Med. Chem. 1997, 40, 3381-3392; h) R. A. Jones in Pyrroles, Part II, The Synthesis, Reactivity and Physical Properties of Substituted Pyrroles, Wiley: New York, 1992.

[16] For selected reviews: a) L. F. Tietze, H. P. Bell, S. Chandrasekhar, Angew. Chem., 2003, 115, 4128-4160; Angew. Chem., Int. Ed., 2003, 42, 3996-4028; b) G. Mehta, V. Singh, Chem. Soc. Rev. 2002, 31, 324-334.

[17] For selected examples of this synthetic-in-origin hybrid structural motive: a) B. Alcaide, P. Almendros, R. Carrascosa, M. C. Redondo, Chem. Eur. J. 2008, 14 , $637-643$; b) for pharmacological activities of some relevant members of this class of hybrid scaffolds : B. Gabriele, G. Salerno, A. Fazio, L. Veltrid, Adv Synth. Catal. 2006, 348, 2212-2222 and references cited therein; c) P. S. Baran, J. M. Richter, D. W. Lin, Angew. Chem. 2005, 117, 615-618; Angew. Chem., Int $E d ., 2005,44,609-612$; d) for hydroxyalkylpyrrole-based inhibitors of $\alpha$ chymotrypsin: D. C. Martyn, A. J. Vernall, B. M. Clark, A. D. Abell, Org. Biomol. Chem., 2003, 1, 2103-2110; e) A. D. Abell and B. K. Nabbs, Bioorg. Med. Chem., 2001, 9, 621-628.

[18] For selected examples: a) A. Ohta, D. Sawamoto, K. P. Jayasundera, H Kinoshita, K. Inomata, Chem. Lett. 2000, 492-493; b) J. E. Bishop, J. F. O'Connell, H. Rapoport, J. Org. Chem. 1991, 56, 5079-5091.

[19] For recent examples of C2-alkylations of pirroles: a) B. M. Trost, C. Mueller, $J$. Am. Chem. Soc. 2008, 130, 2438-2439; b) S.-H Cho, S. Chang, Angew. Chem. 2008, 120, 2878-2881; Angew. Chem. Int. Ed. 2008, 47, 2836-2839; c) D. A. Evans, K. R. Fandrick, Org. Lett. 2006, 8, 2249-2252; d) C. Palomo, M. Oiarbide, B. G. Kardak, J. M. García, A. Linden, J. Am. Chem. Soc. 2005, 127 4154-4155; e) N. A. Paras, D. W. C. MacMillan J. Am. Chem. Soc. 2001, 123 , 4370-4371.

[20] For selected exemples: a) M. L. Crawley, I. Goljer, D. J. Jenkins, J. F Mehlmann, L. Nogle, R. Dooley, P. E. Mahaney, Org. Lett. 2006, 8, 5837-5840; b) K. Hiroya, S. Matsumoto, M. Ashikawa, K. Ogiwara, T. Sakamoto, Org. Lett. 2006, 8, 5349-5352; c) T. Ishikawa, T. Aikawa, S. Watanabe, S. Saito, Org. Lett. 2006, 8, 3881-3884; d) S. Kamijo, C. Kanazawa, Y. Yamamoto, J. Am. Chem. Soc. 2005, 127, 9260-9266; e) J. T. Binder, S. F. Kirsch, Org. Lett. 2006, 8 , 2151-2153; f) T. J. Harrison, J. A. Kozak, M. Corbella-Pane, G. R. Dake, J. Org Chem. 2006, 71, 4525-4529; g) R. V. Ohri, A. T. Radosevich, K. J. Hrovat, C. Musich, D. Huang, T. R. Holman, F. D. Toste, Org. Lett. 2005, 7, 2501-2504 h) D. J. Gorin, N. R. Davis, F. D. Toste, J. Am. Chem. Soc. 2005, 127, 11260 11261; i) A. V. Kel'in, A. W. Sromek, V. Gevorgyan, J. Am. Chem. Soc. 2001 $123,2074-2075$

[21] a) D. Tejedor, D. Gonzalez-Cruz, F. Garcia-Tellado, J. J. Marrero-Tellado, M. L. Rodriguez, J. Am. Chem. Soc. 2004, 126, 8390-8391; b) J. I. Dickstein, S. I Miller in The Chemistry of Functional Groups. The Chemistry of $C \equiv C$, Part 2 , (Ed. S. Patai), Wiley, Chichester, 1978, Ch. 19, pp. 813-855; c) E. Winterfeldt, Angew. Chem. 1967, 79, 389-400; Angew. Chem. Int. Ed. 1967, 6, 423-434.

[22] Chem. Rev. Special issue: "Frontiers in organic synthesis", (Ed.: P. A. Wender), 1996, 96, 1-600.

[23] Microwave heating was performed in a commercial single-mode microwave CEM Discover oven.

[24] The crystal structure has been deposited at the Cambridge Crystallographic Data Centre and allocated the deposition number CCDC 695860

[25] We have spectroscopic evidence showing that compound 3 is an intermediate of the reaction and leads to the final product (See Supporting Information). 
Entry for the Table of Contents (Please choose one layout only)

Layout 2:

\section{Domino synthesis \\ David Tejedor,* Sara López-Tosco, Javier González-Platas and Fernando García-Tellado* Page - Page}

From conjugated tertiary skipped diynes to chain-functionalized tetrasubstituted pyrroles.

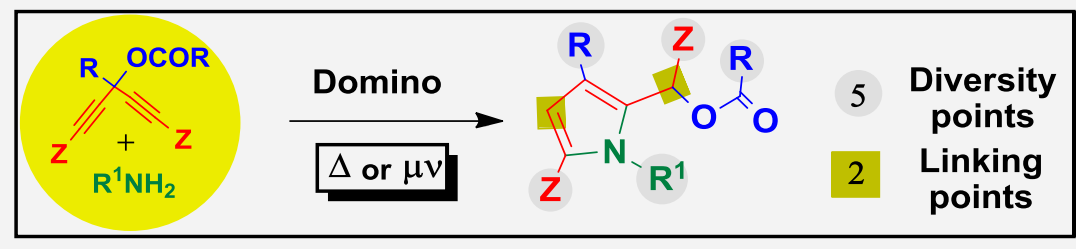

Symmetry breaking of 1,4-diyne for complexity generation. The scaffolds via nucleophilic amine synthetic manifold operates addition onto one of the two following a domino construction equivalent alkynoate units affords principle and it entails an azachain-functionalized tetrasubstituted Michael addition, an 5-endo-digonal pyrroles featuring five points of cyclization and a [3,3]-sigmatropic functional diversity and two points rearrangement 